\title{
Trajectories of Parenting Styles and Delinquency: An Examination Using a Sample of African-Americans
}

\author{
Anthony Smith ${ }^{1}$, Emma Leigh E. Kirchner ${ }^{1}$, George E. Higgins ${ }^{*}, 2$ and Dave Khey ${ }^{3}$ \\ ${ }^{1}$ University of Louisville, USA \\ ${ }^{2}$ Department of Justice Administration, 208 Brigman Hall, 2301 South Third Street, University of Louisville, Louisville, \\ KY 40292, USA \\ ${ }^{3}$ Loyola University New Orleans
}

\begin{abstract}
The development of parenting style typologies has led to a number of studies that have linked them to delinquency. Although a number of studies have shown that parenting style typologies have a link with delinquency, studies have not shown whether there were distinct trajectories of parenting styles and delinquency. These studies have not considered this in a sample of only African-Americans. Using data from the NLSY97 that only contains 725 AfricanAmericans, our results show that three distinct trajectory groups of parenting styles are present for residential mothers and for residential fathers. In addition, we show that three distinct trajectory groups of delinquency are present. Our results show that a joint analysis of the intersection of these trajectories does not clarify the links between parenting styles and delinquency over time. Implications and directions for future research are highlighted.
\end{abstract}

Keywords: Parenting Styles, Delinquency, Trajectories, African-Americans.

\section{TRAJECTORIES OF PARENTING STYLES AND DELINQUENCY: AN EXAMINATION USING A SAMPLE OF AFRICAN-AMERICANS}

In 1966, Baumrind presented a typology of parenting. Briefly, the typology consists of three parenting styles: permissive parents (i.e., non-punitive), authoritarian parents (i.e., shaping, controlling, and evaluating the behavior and attitudes of a child by following a set standard of conduct including those theologically motivated), and authoritative parents (i.e., directs the child's activities by using a rational, issue-oriented manner). Reseachers further developed this typology to include neglecting-rejecting parenting (i.e., undemanding and unresponsive to the child) [1]. These typologies have been linked to delinquency [3]. In addition, researchers' have shown that parenting practices have a link to delinquency [3]. The issue with these studies is that they have typically used cross-sectional data for their examinations. To rectify this problem, two studies have used longitudinal data to examine the trajectories of the parenting styles $[2,3]$ and the trajectories of delinquency. One study did not provide an inclusive measure of parenting so a substantial amount of the parenting styles had to be inferred [2]; thus, the literature is still problematic. The other study did not examine the trajectories of the parenting styles over time, nor did they parcel their data to examine AfricanAmericans only [3]. Thus, a gap is present in the empirical literature on parenting styles.

*Address correspondence to this author at the Department of Justice Administration, 208 Brigman Hall, 2301 South Third Street, University of Louisville, Louisville, KY 40292, USA; Tel: (502) 852-0331;

E-mail: gehigg01@gwise.louisville.edu
African-Americans are important to study for a number of reasons. African-Americans have been shown to be the most criminogenic group, per capita [4,5]. Researchers have shown that African-Americans are also the most violent $[6$, 7]. The lack of literature that examines the link between that trajectories parenting styles and trajectories of delinquency of adolescent African-Americans is an important gap that needs to be considered and rectified.

The purpose of the present study is to provide an examination of (1) how parenting styles over time may follow distinct pathways, (2) how these parenting styles may link with delinquency, and (3) how this process works in the context of African-Americans. This is important because it will fill the gaps in two literatures: parenting styles and delinquency. To fill this gap the present study begins by presenting the parenting styles literature that is followed by Moffitt's dual taxonomy $[8,9]$. Then, the methods come that are followed by the analysis plan, results, and discussion.

\section{BAUMRIND PARENTING STYLES}

A number of researchers have contributed to the criminological literature that there is a link between parenting and delinquency. For instance, social control theorist have argued and shown that a lack of bonding with a child is likely to lead to delinquency [10-12]. Social learning theorist argued that poor parenting teaches children to become delinquent [13]. The empirical literature has shown that parenting has an important link with delinquency [14].

Baumrindadded to this literature and developed a typology of the various methods of parenting style and highlighted the effects of authoritative parenting on children in the child-rearing process [15]. Her typologies included: permissive parents, authoritarian parents, and authoritative 
parents. They were later elaborated upon and added to by Maccobyand colleagues when they added neglectingrejecting [1]. These typologies are meant to be fluid and describe only the general parenting style and should not be considered mutually exclusive.

Permissive parents attempt to be nonpunitive, acceptant, and affirmative towards the child's impulses, desires, and actions $[15,16]$. The only methods of control that are utilized include manipulation and reasoning. The parenting becomes a democratic process with the child giving equal input about policy decisions and family rules. The parent rarely gives or expects household responsibilities and orderly behavior. The role of a parent in this case is to be a resource, not a role model or as a guide that is responsible for aiding in the maturation process. Instead, the children are allowed to regulate their own activities $[15,16]$.

The authoritarian has the goal of shaping, controlling, and evaluating the behavior and attitudes of a child by following a set standard of conduct including those theologically motivated and prescribed by a higher power $[15,16]$. Obedience is considered to be a virtue and punitive punishment is favored to realign perceptions of self-will when the child's actions or beliefs conflict with the parent. Best viewed as a manager, this parenting type strives to keep children in their place, restricting his autonomy, and assigning household responsibilities in order to instill respect for work. Preservation of order is looked at as the primary goal, and indoctrinating the child into an existing system is the only acceptable method. For this reason, there is no discussion about the course of authority and the child is not permitted decision-making $[15,16]$.

The authoritative parent directs the child's activities by using a rational, issue-oriented manner $[15,16]$. Verbal give and take is encouraged, including providing children with the reasoning behind the rules and policies, and an attempted mediation process for differences in opinion between the adult and child. In this way, the parent provides both autonomous self-will and disciplined conformity. Enforcing the parental perspective and simultaneously recognizing the child's individual interests can obtain a balanced and fair relationship [15, 16]. Parenting decisions are made and upheld based on mutual respect, recognized power and reinforcement and not group consensus or the child's preference.

A fourth parenting style was introduced later and is labeled as Neglecting-Rejecting [1,17]. This parenting style is both undemanding and unresponsive to the child. Limits are not set and the parent's involvement in the livelihood of the child merely extends to providing physical resources for the child with no emotional attachment. No forms of discipline or emotional support are present.

These studies have been cogently summarized and analyzed in a meta-analysis [18]. Their meta-analysis consisted of 161 published and unpublished studies that have examined these parenting typologies in the context of delinquency. Their results indicated that parenting accounted for 11 percent of the variance in delinquency. The weakest links were found for authoritative and authoritarian control, and the strongest links were found for psychological control (i.e., support). Importantly, the majority of these studies are cross-sectional and they do not take trajectories of parenting styles into account. In our view, to gain insight into how parenting plays a role in delinquency, it is important to understand how it changes over time because theorists [9] have consistently argued that delinquency changes over time. Further, these theorists have provided some information on how parenting changes in the context of changes in delinquency. Thus, we believe that Baumrind's $[15,16]$ and Maccoby and colleagues [1] version of parenting styles and Moffitt's dual taxonomy of delinquency will work together in an attempt to explain how parenting style can affect the long-term antisocial attitudes and delinquent actions of an individual. To provide an understanding of our position, we present Moffitt's dual taxonomy [8].

\section{DUAL TAXONOMY}

Moffitt's [8] dual taxonomy is one in many different theories used to understand delinquency in the developmental perspective. Moffitt [8] argues that there may be two types of offenders that may be present in longitudinal data. One group is referred to as life-course persistent. Lifecourse persistent offendersbegin committing delinquency at an early age, and they continue delinquency and offending throughout their adulthood. At an early age, they show antisocial behavioral traits including biting and hitting at the age of four and will continue and escalate to offend through shoplifting, truancy, stealing cars, and later violent behaviors persistently throughout their life. The type of deviance performed varies across situations and can encompass every type of interaction. For instance, they lie at home, shoplift at stores, fight in bars, and embezzle from work [8]. Causes of life-course persistent offending go beyond, and have little to do with peer associations. Early life issues including heredity, poor prenatal care, possible drug use by their mothers, as well as complicated births may be contributors to issues with neuropsychological development. Early parenting issues such as poor stimulation, nutrition and even affection can affect life-course behavioral attitudes. The children that are born into this situation are often not born into a supportive environment where they can receive adequate care and socialization [8].

The second group is referred to as the adolescencelimited. As the name implies, they have a short stent of delinquent activity that appears and ends abruptly during the ages of 11-20. Adolescence-limited antisocial behavior best summarized by its discontinuity. This type of delinquency is associated with an abrupt beginning and end to criminality in a person that did not display it early in life and will not display it later [8]. It is largely based on social interaction and is attributed to a maturity gap, which is the difference between physical age and emotional maturity. They lack consistency even within their "criminal career" by selectively following and ignoring rules [8]. Antisocial and prosocial behaviors are used in tandem depending on which provides the greater positive reward in a given situation. This reward is at its highest in a social group setting where it can be observed. Adolescence-limited deviance is a result of "social mimicry" adults [8]. This is done to show mature status, and the associated power and privilege. Ironically, this is also the reason that further delinquent activity ceases after adulthood [8]. 
Moffitt [8] adjusted her theory to include the subgroup low-level chronics. This group is distinct from the other two on the basis of consistency of offending through the lifecourse. They perform lifetime antisocial activities but have periods of inactivity or conformity to prosocial practices. Their early life is characterized by antisocial personality traits and experiences that prevent them from fully socializing. This continues later in life and provides a reduced stake in conformity, which allows for occasional criminality [8].

Moffitt's $[8,9]$ has been empirically examined in several studies. The results of these studies show support for Moffitt's [8,9] views [19-22]. While these results have shed some light on the empirical support for Moffitt's taxonomy, only a few of these studies are able to provide an understanding of how changes in parenting styles play a role in changes in delinquency.

The literature that directly examines the changes in parenting styles and delinquency is small [2, 3]. The literature shrinks to two studies that directly examine the trajectories of Baumrind's [10,11] and Maccoby et al.'s [1] parenting styles in the context of trajectories of delinquency. Gorman-Smith, Tolan, and Henry [2] published the first study to take up this issue. They used four waves of data from the Chicago Youth Development Study $(n=288)$ that is comprised of African-American and Latino boys and their caregivers. Gorman-Smith et al. [2] showed that those that were subjected to low in discipline, monitoring, structure, cohesion, and beliefs (i.e., neglectful) were at an increased risk for delinquency, but those that were subjected to high discipline, monitoring, structure, cohesion, and beliefs were less likely to be involved with delinquency. High task oriented families (i.e., authoritarian style) were more likely to be involved in delinquency. This study shows that different trajectories of parenting styles do have different outcomes for delinquency.

Hoeve et al. [3] attempted to build on Gorman-Smith et al. [2] by performed a study that extended beyond four waves of data. They used the Pittsburgh Youth Study that followed adolescents from ages 7 to $19(n=843)$. The adolescents in this study were multi-racial/ethnic. They found that the authoritarian parenting style and the serious persistent trajectory were closely related. High levels of punishment combined with low levels of communication were also associated with increased involvement in all levels of persisting and desisting delinquency [3]. It is important to note a few limitations of this study. First, Hoeve et al. [3] only used a cross-sectional latent class analysis to determine the groups of parenting styles. This restricts that understanding of parenting styles across time. Second, Hoeve et al. [3] used a multi-racial/ethnic sample that restricted their ability to address how parenting styles relate to delinquency for African-Americans alone. The results from this study and the Gorman-Smith et al. (2000) study leave two gaps in our understanding: (1) do parenting styles over time may follow distinct pathways, and (2) do these parenting styles may link with delinquency?

Moffitt's [9] review of the literature on her taxonomy argued that the plight of African-Americans in delinquency may be explained in parenting issues. Specifically, Moffitt [9] argued that poor prenatal care may be responsible for their position into a life-course persistent offending typology, and that poor social bonds may be responsible for their position into the adolescent limited offending typology. To date, few researchers have examined this perspective [23, 24]. The researchers that have examined this view have not examined this perspective in the context of parenting styles; thus, the literature has a third gap: does the developmental taxonomy process works in the context of AfricanAmericans?

\section{THE PRESENT STUDY}

The purpose of the present study is to address the two gaps that have been left in previous research $[2,3]$ that directly examined the link between the trajectories of parenting styles and trajectories of delinquency in a few ways. First, this study uses only an African-American sample. Moffitt [9] argued that the trajectories of delinquency would be different African-Americans and other races. In addition, African-Americans are viewed as the most criminogenic racial group [4,5], and an understanding of changes in parenting styles may provide some insight as to why this occurs. In addition, the use of African-Americans is important because little research has focused on AfricanAmerican trajectories of offending. Second, the two studies that have examined this premise have been limited to cityspecific samples that reduce the generalizability of their results. As will be documented below, our study is important because we provide insights to the changes in parenting styles using a national sample to improve the generalizability of our results.

\section{METHODS}

\section{Sample and Procedures}

The data for this study came from the National Longitudinal Survey of the Youth (NLSY97). The survey was originally designed to capture the longitudinal factors that influence youths' transition from school to workplace. The survey does capture a number of demographic and lifestyle measures. The factors that are relevant to the present study are parenting style and delinquency. This panel survey began with 8,984 youth that were born between 1980 and 1984. ${ }^{1}$ The survey includes a supplemental sample of Hispanic and African-American youth. This survey has been conducted annually since 1997.

To arrive at the data for the present study we used a number of criteria. First, the data for the present study came from four rounds of the survey, 1997 to 2000, and they are exclusively African-American. Second, these individuals were between 13 to 16 years old during the 1997 to 2000 period. This period of life is important because it provides an opportunity for the respondents to follow the age-crime curve, and it provides the respondents an opportunity still be directly influenced by their parents parenting style. Thus, we

\footnotetext{
${ }^{1}$ The NLSY97 survey was typically carried out between February to August of 1997. The data were actually collected between November and April of the following years. This may allow for some overlap of individuals in the data. We monitored this process and found that 7 individuals in our data appeared more than once. So to not bias the data, we removed these 7 individuals. T-tests show that the removal of these individuals did not result in substantively different results. The results of the t-tests are available from the third author on request.
} 
believe that our data allows us to examine the intersection between trajectories of parenting styles and trajectories of delinquency.

In addition to these criteria, because we used a longitudinal methodology, missing data are a reality $[25,26]$. We examined the extent of missing data in our parenting style measure and our delinquency measure using t-tests. The missing data for parenting style and delinquency were small. From this set of procedures, we used a sample of 725 African-Americans. Of these 725 African-Americans, 59.2\% were female and $40.8 \%$ were male.

\section{Measures}

Parenting Style. The parenting style measure follows Maccoby and Martin [1] who proposed a four-style typology that is created by crossing two global dimensions of parenting: demandingness and responsiveness. Two items captured were used to create this measure: 1) when you think about how s/he acts towards you, in general, would you say that $\mathrm{s} / \mathrm{he}$ is (1) very supportive, (2) somewhat supportive, or (3) not very supportive? 2) In general, would you say that $\mathrm{s} /$ he is (1) permissive or (2) strict about making sure you did what you were supposed to do? The measures were split based on residential mother and residential father. Regardless of the split, higher scores indicate authoritarian parenting styles.

Delinquency. The delinquency measure that we used was an additive measure of five items. The five items were, "Have you purposely destroyed property in [during the current year]?", "Have you stolen anything under 50 dollars [during the current year]?", "Have you stolen anything over 50 dollars [during the current year]?", "Have you committed a property delinquency [during the current year]?", "Have you attacked to hurt someone or fight with them [during the current year]?" The respondents indicated whether they had or had not (1) yes or (0) no. The scores ranged from 0 to 5 with higher scores indicating that they committed more criminal activity. The internal consistency of the items for each of the years was acceptable between 0.65 to 0.80 .

\section{ANALYSIS}

The analysis proceeds in several steps. First, we present the descriptive statistics for the measures. Second, we performed bivariate correlations to examine the shared variance among the measures. Third, we perform trajectory analyses of parenting styles and delinquency using the SASbased ProcTraj procedure to examine the extent to which there are distinct developmental pathways for parenting styles and delinquency. Used in many studies in criminology and psychology $[3,22,23]$, the trajectory methodology is properly suited for identifying distinct trajectories or groups of individuals who follow distinct pathways of a particular behavioral outcome. In this study, the trajectory method followed a quadratic form and employed the ZIP options for delinquency and the CNORM options for parenting styles from ProcTraj. Two pieces of information were used to determine the optimal form and number of groups:Bayesian Information Criterion (BIC) and posterior probabilities. Nagin [27] argued that the maximized BIC and posterior probabilities that were $=>0.70$ were enough information to suggest that the optimal form and number of groups have been found. Fourth, we performed a dual trajectory analysis to determine how the changes in parenting styles intersect with the changes in delinquency.

\section{RESULTS}

\section{Step 1}

Table 1 presents the descriptive statistics for the residential mother sample. The mean level of the parenting style is decreasing over time for both residential mothers and residential fathers. This indicates that the mothers are becoming more permissive. Table 1 shows that delinquency is also decreasing.

\section{Table 1. Descriptive Statistics}

\begin{tabular}{|c|c|c|}
\hline \multicolumn{3}{|c|}{ Descriptive Statistics } \\
\hline Variable & Mean & Std. Deviation \\
\hline \hline Mother's Parenting Style 1997 & 1.61 & 0.50 \\
\hline Mother's Parenting Style 1998 & 1.59 & 0.52 \\
\hline Mother's Parenting Style 1999 & 1.60 & 0.51 \\
\hline Mother's Parenting Style 2000 & 1.48 & 0.54 \\
\hline Father's Parenting Style 1997 & 1.59 & 0.52 \\
\hline Father's Parenting Style 1998 & 1.56 & 0.53 \\
\hline Father's Parenting Style 1999 & 1.51 & 0.55 \\
\hline Father's Parenting Style 2000 & 1.42 & 0.58 \\
\hline Delinquency 1997 & 0.84 & 1.11 \\
\hline Delinquency 1998 & 0.51 & 0.92 \\
\hline Delinquency 1999 & 0.46 & 0.96 \\
\hline Delinquency 2000 & 0.32 & 0.77 \\
\hline
\end{tabular}

\section{Step 2}

Table 2 presents the bivariate correlations for residential mother (Panel A) and residential father (Panel B) parenting styles and delinquency. Panel A shows that the parenting style measures for the residential mother have proper levels of test-retest reliability, and that delinquency also has proper levels of test-retest reliability. Panel B shows that the parenting style measures for residential fathers have proper levels of test-retest reliability. The correlations between parenting style and delinquency are weak and sporadic in Panels A and B, which is counter to the literature (see Hoeve et al.'s, 2009 meta-analysis [18]).

Step 3

Fig. (1) presents the trajectory analysis for residential mother. Based on the BIC and satisfactory posterior probabilities (i.e., $>0.70$ ), three trajectory groups were found for parenting style. This is consistent with the previous literature [3]. Trajectory group G1 follows a stable low-level path that indicates neglectful parenting. Trajectory group G2 follows a steadily decreasing path that indicates authoritative that moves to neglectful. Trajectory group G3 follows a stable high-level path that indicates authoritative parenting. 
Table 2. Bivariate Correlations

Panel A: Mother's Parenting Styles and Delinquency

\begin{tabular}{|c|c|c|c|c|c|c|c|c|}
\hline Variable & 1 & 2 & 3 & 4 & 5 & 6 & 7 & 8 \\
\hline 1. Mother's Parenting Style 1997 & 1.00 & & & & & & & \\
\hline 2. Mother's Parenting Style 1998 & $0.24 *$ & 1.00 & & & & & & \\
\hline 3. Mother's Parenting Style 1999 & $0.32 *$ & $0.40^{*}$ & 1.00 & & & & & \\
\hline 4. Mother's Parenting Style 2000 & $0.21 *$ & $0.27 *$ & $0.36^{*}$ & 1.00 & & & & \\
\hline 5. Delinquency 1997 & 0.00 & -0.08 & -0.05 & -0.04 & 1.00 & & & \\
\hline 6. Delinquency 1998 & -0.02 & -0.04 & $-0.09 *$ & -0.06 & $0.30 *$ & 1.00 & & \\
\hline 7. Delinquency 1999 & -0.05 & -0.07 & $-0.11 *$ & $-0.10^{*}$ & $0.31 *$ & $0.31 *$ & 1.00 & \\
\hline 8. Delinquency 2000 & -0.01 & 0.01 & -0.07 & $-0.09^{*}$ & $0.28 *$ & $0.26^{*}$ & $0.47 *$ & 1.00 \\
\hline
\end{tabular}

Panel B: Father's Parenting Styles and Delinquency

\begin{tabular}{|c|c|c|c|c|c|c|c|c|}
\hline 1. Father's Parenting Style 1997 & 1.00 & & & & & & & \\
\hline 3. Father's Parenting Style 1999 & $0.27 *$ & $0.33 *$ & 1.00 & & & & & \\
\hline 4. Father's Parenting Style 2000 & $0.24 *$ & $0.42 *$ & $0.35 *$ & 1.00 & & & & \\
\hline 6. Delinquency 1998 & -0.01 & -0.04 & $-0.14 *$ & $-0.13 *$ & $0.30^{*}$ & 1.00 & & \\
\hline 7. Delinquency 1999 & -0.07 & -0.05 & $-0.19 *$ & -0.09 & $0.31 *$ & $0.31^{*}$ & 1.00 & \\
\hline 8. Delinquency 2000 & 0.01 & -0.07 & -0.05 & $-0.15^{*}$ & $0.28 *$ & $0.26^{*}$ & $0.47 *$ & 1.00 \\
\hline
\end{tabular}

Fig. (1) presents the trajectory analysis for residential fathers. The BIC and satisfactory posterior probabilities (i.e., $>0.70$ ), show that three trajectory group represent these parenting styles. As with residential mothers, the trajectory groups are consistent with the patterns from Hoeve et al. [3]. To clarify, trajectory group G1 follows a relatively low trajectory that indicates neglectful parenting. Trajectory group G2 follows a high trajectory group that indicates authoritarian parenting, and trajectory group G3 follows a declining path that indicates authoritative parenting.

Fig. (1) presents the trajectory analysis for delinquency. The BIC and satisfactory posterior probabilities (i.e., $>0.70$ ) indicated that a three group model best represented these data. Trajectory group G1 follows a low stable path of delinquency, trajectory group G2 follows a desisting path of delinquency, and trajectory group G3 follows a high but changing path. Three trajectory groups are consistent with the results of Piquero [28] that found that ProcTraj consistently produces 3 to 5 trajectory groups. In addition, these results are consistent with Moffitt's [8,9] view that three groups would be present in the data.

\section{Step 4}

Fig. (2) presents the dual trajectory analysis of parenting style and delinquency in two panels. Panel A presents the joint trajectory of residential mother parenting style and delinquency. The the most delinquent group--delinquency group G3--does not show a link with differences in parenting styles. This is not the case for the other delinquency groups. For instance, delinquency trajectory group G1--the lowest delinquency group--has more individuals that are also following the parenting style G3 group, and the same can be said for delinquency trajectory group G2. These results indicate that the residential mother parenting styles do not clearly delineate between the most delinquent groups.

Panel A. Residential Mother Parenting Style and Delinquency.

Panel B presents the joint trajectory analysis for residential father and delinquency trajectories. For delinquency trajectory group G3, it appears that the more individuals following parenting style trajectory group G2 are in this group; however, it appears that this is the case for all of the delinquency trajectory groups. These results indicate that it is not clear whether the harshest parenting style has a clear link with delinquency.

\section{DISCUSSION}

In an effort to contribute to two distinct but related literatures (i.e., parenting styles and delinquency), this article relied on Moffitt's $[8,9]$ taxonomic approach to understand the extent to which the distinct developmental parenting style trajectories relate to delinquency trajectories among a large sample of African-Americans in the NLSY97. Several results emerged from this study. 

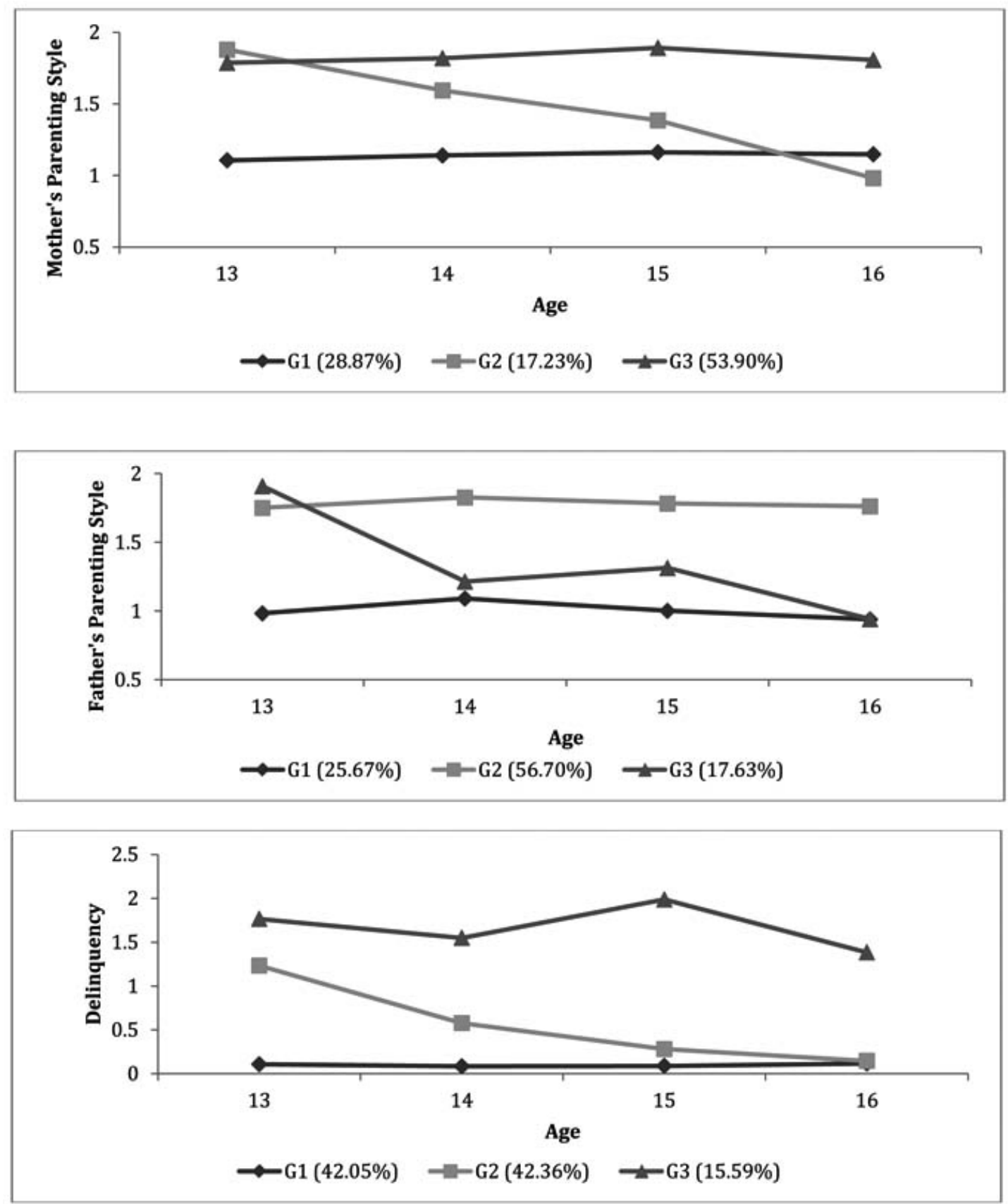

Fig. (1). Residential Mother Parenting Style.

First, the analysis indicated distinct groups of individuals followed distinct trajectories associated with residential mothers and residential father parenting styles and delinquency. These results are consistent with the developmental literature on delinquency $[8,9,28]$ and parenting style [3]. These results suggest the importance of unpacking the heterogeneity in both concepts. Residential mothers had three parenting styles: high stable, low stable, and decreasing. Residential fathers also had three parenting styles: high stable, low stable, and decreasing. These results are consistent with Hoeve et al. [3] who found three groups of parenting styles. It is important to remember that Baumrind theorized that four groups of parenting were present. The results here, along with others [3], show that this may not be the case in all data. Our results stand out because we used longitudinal data; thus, we argue over time the parenting styles may not be as complex as presented by Baumrind. This is also important because it has not come to fruition in a sample of African-Americans. Further, the results indicated three trajectory groups of delinquency were found: stable low-level delinquency, high unstable delinquency, and those that appear to be desisting. Our results are consistent Moffitt's typology of criminal behavior over the life course. In other words, some AfricanAmericans will stably commit delinquency over time. Some will commit delinquency at a high level over time, and some will desist from delinquency.

Second, the dual trajectory analysis shows the link between parenting styles and delinquency varies for the type of parent. This result is consistent with previous research [3]. 
Panel A. Residential Mother Parenting Style and Delinquency

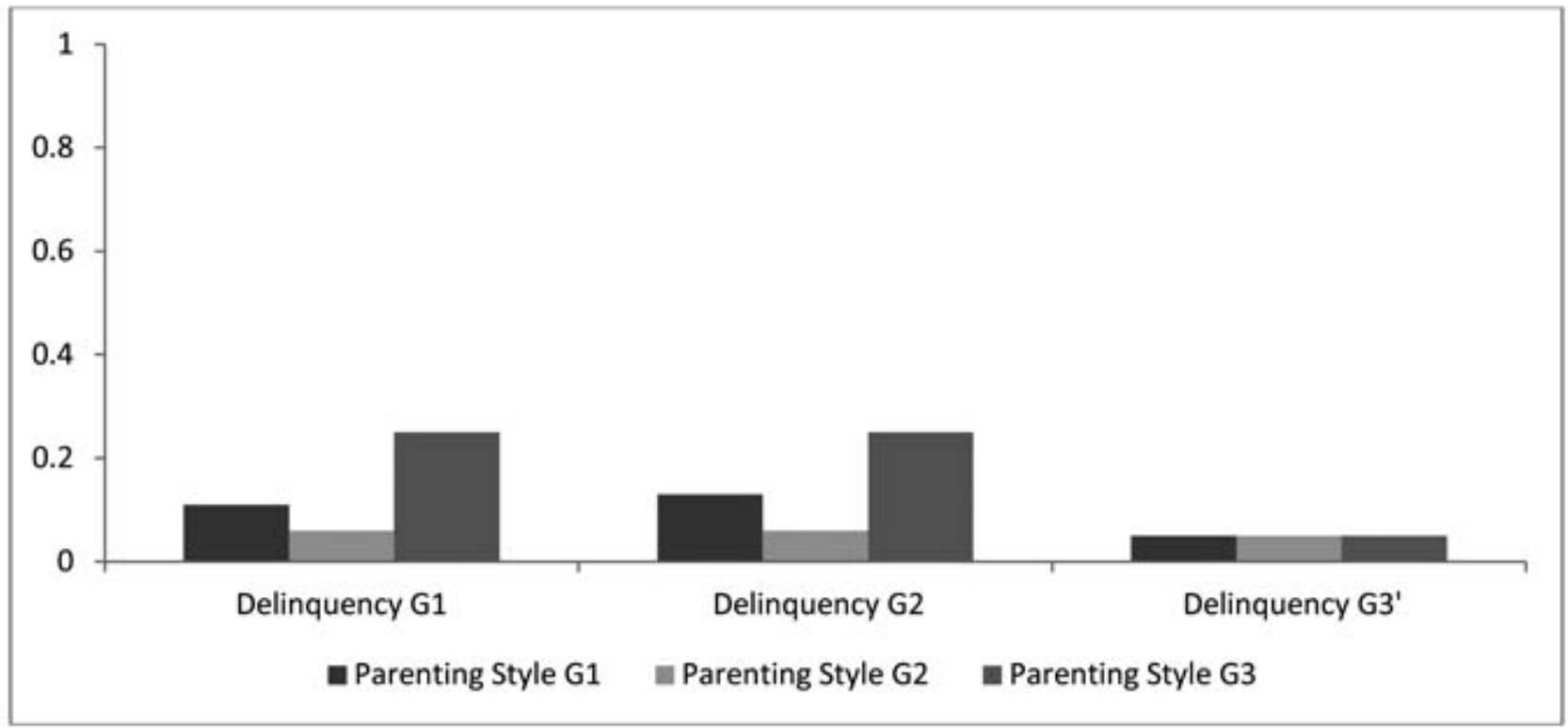

Panel B. Residential Father Parenting Style and Delinquency.

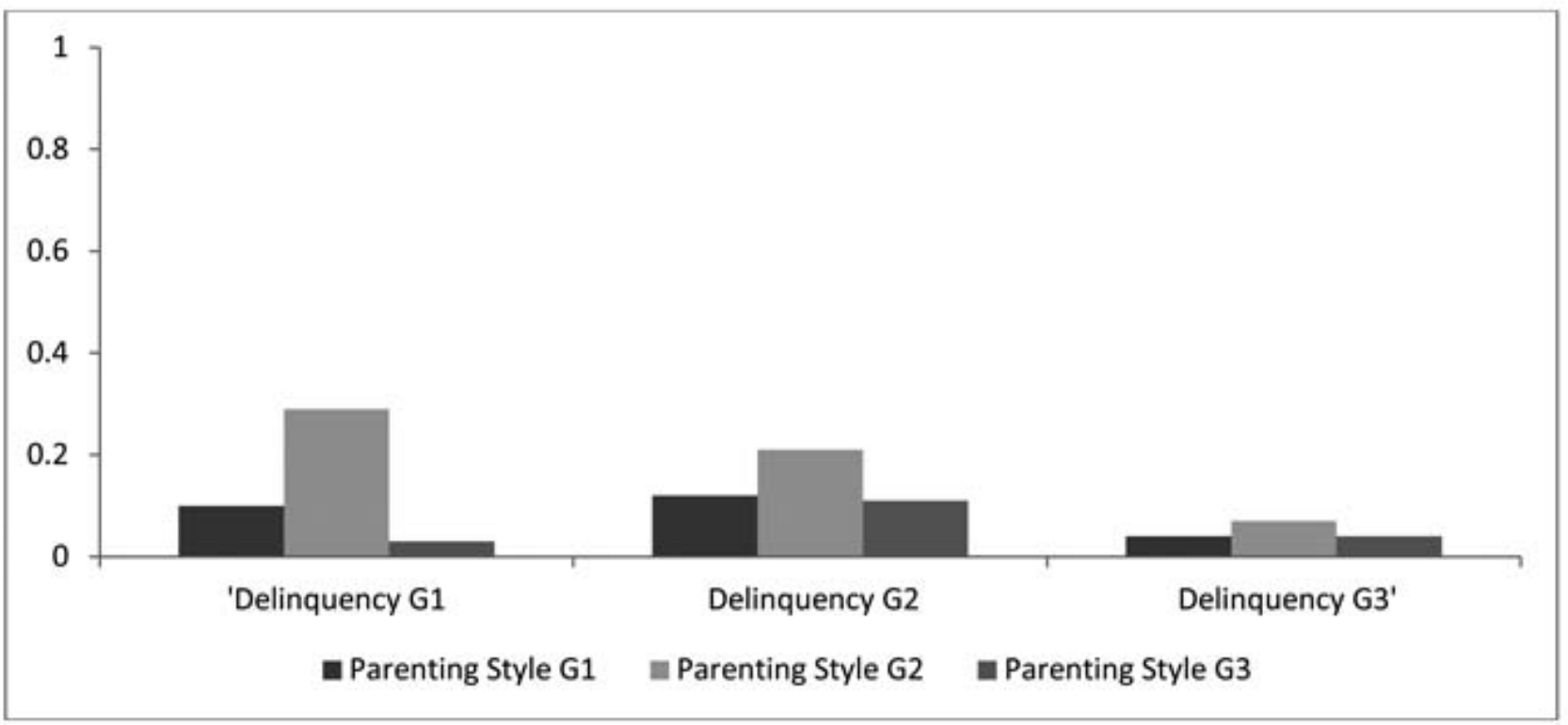

Fig. (2). Dual Trajectory Analysis.

For instance, residential mother's shows that the high unstable group is likely to be influenced the same by the three parenting styles. The high parenting style is more likely to put individuals in the stable low-level delinquency and apparent desisting groups. Third, the dual trajectory analysis shows the link between parenting styles and delinquency varies for the residential father. The high stable trajectory group seems to place individuals in all of the delinquency groups.

In our view, the importance of parenting styles, which has commonly been believed to be important for delinquency [18], may not be the case for African-Americans. For instance, the trajectories of parenting styles are not able to distinguish between the trajectory groups of delinquency. To clarify, the parenting styles are not able to distinguish between the most delinquent trajectory groups. This is highlighted in the residential fathers, and seen in the residential mothers. We believe that parenting styles may be different for African-Americans than other groups. Hoeve et al. [3] used data that came from multiple races/ethnicities and did not target African-Americans. This may be difference between our two studies.

From this analysis, research suggests that policy implications are necessary. Our results suggest that parenting styles may not be as important to delinquency as first thought in the literature, in a sample of African-Americans. 
We are not implying that there is not a connection between parenting styles and delinquency, but that it could be overstated. With this in mind, we believe that parenting courses offered to new mothers and fathers will assist in reducing instances in delinquency. Some researchers have examined this view and showed that it is important to reduce delinquency [14].

Although the results are among the first set of empirical findings that have provided a trajectory-based examination of parenting styles and delinquency among AfricanAmericans, but several limitations reduce our ability to reach a more definitive statement regarding these two concepts. First, our ability to provide a comprehensive examination of parenting styles was impeded by the inability to use a complete measure of parenting styles. It is worth noting, the measure that we used is consistent with previous literature. Second, due to data constraints, we were not able to capture parenting styles and delinquency earlier in life. Some have argued that parenting and parenting styles are more important in pre-teen period of life $[1,15]$. While this may make a difference, Hoeve et al. [3] arrived at similar results using a multi-racial/ethnic sample.

Despite these limitations, our study has generated some unique insights into the heterogeneity in both parenting styles and delinquency, and their joint overlap in particular, and has further contributed to the literature linking parenting styles and delinquency for African-Americans. Clearly, this study is not the last word or examination of these links, it does provide some unique insights and results that can help guide future theoretical and empirical inquiry.

\section{ACKNOWLEDGEMENT}

We thank you anonymous reviewers for their helpful comments. We also thank the editor for his insight.

\section{CONFLICT OF INTEREST}

None declared.

\section{REFERENCES}

[1] Maccoby EE, Marting JA. Socialization in the context of the family: Parent-child interaction. Mussen P, Heterington EM, Eds. Handbook of Child Psychology: Socialization, personality, and social development. New York: Wiley 1983; pp. 1-101.

[2] Gorman-Smith D, Tolan PH, Henry DB. A developmentalecological model of the relation of family functioning to patterns of delinquency. J Quant Crim 2000; 16: 169-98.

[3] Hoeve M, Blokland A, Dubas J, Loeber R, Gerris J, can der Laan P. Trajectories of delinquency and parenting styles. J Abnorm Psychol 2008; 26: 223-35.

[4] Walker D, Spohn C, DeLone M.The color of justice: Race and crime in America. Belmont, CA: Wadsworth 2003.

[5] Gabbidon SL, Greene HT. Race and crime. Thousand Oaks: Sage Publications 2005.

[6] Snyder HM, Sickmund M. Juvenile offenders and victims: A national report. Washington, DC: OJJDP, U.S. Department of Justice 1995.
[7] Farrington DP, Loeber R, Stouthamer-Loeber M. How can the relationship between race and violence be explained? Hawkins DF, Ed. Violent Crime: Assessing race and ethic differences. Cambridge : Cambridge University Press 2003; 213-37.

[8] Moffitt TE. "Life-course persistent" and "adolescent-limited" antisocial behavior: A Developmental taxonomy. Psych Rev 1993; 100: 674-774.

[9] Moffitt TE. Life-Course-Persistent and Adolescence-Limited Antisocial Behavior: A 10-Year Research Review and a Research Agenda. Lahey BB, Caspi A, Moffitt TE, eds. Causes of conduct disorder and juvenile delinquency. 2003; 49-75.

[10] Hirschi T. Causes of delinquency. Berkeley, CA: University of California Press 1969.

[11] Hirschi T. Causes of delinquency; with a new introduction Piscataway: Transaction Publishers 2002.

[12] Gottfredson M, Hirschi T. A general theory of crime. Stanford: Stanford University Press 1990.

[13] Akers RL. Social learning and social structure: A general theory of crime and deviance. Boston: Northeaster University Press 1998.

[14] Piquero AR, Farrington DP, Welsh BC, Tremblay R, Jennings W. Effects of early family/parent programs on antisocial behavior and delinquency. J Exper Crim 2009; 5; 83-120.

[15] Barumrind D. Effects of authoritative parent control on child behavior. Child Dev 1966; 37: 887-907.

[16] Baumrind D. Current patterns of parenting authority. Dev Psychol Monograph 1971; 4: 1-103.

[17] Baumrind D. The influence of parenting style on adolescent competence and substance abuse. J Easy Adol 1991; 11: 56-95.

[18] Hoeve M, Dubas J, Eichelshiem V, can der Laan P, Smeenk W, Gerris J. The relationship between parenting and delinquency: A meta-analysis. J Abnorm Psychol 2009; 37: 749-75.

[19] Ge X, Donnellan MB, Wenk E. Differences in personality and patterns of recidivism between early starters and other serious male offenders. J Am Acad Psych Law 2003; 31: 68-77.

[20] Moffitt TE, Caspi A, Dickson N, Silva PA, Stanton WR.Childhood-onset versus adolescent-onset antisocial conduct problems in males: Natural history from ages 3 to 18 years. Dev Psychopathol 1996; 8: 399-424.

[21] Moffitt TE, Caspi A, Rutter M, Silva PA. Sex differences in antisocial behavior: Conduct disorder, delinquency, and violence in the Dunedin longitudinal study. Cambridge : Cambridge University Press 2001

[22] White J, Moffitt TE, Caspi A, Jeglum-Bartusch D, Needles D, Stouthamer-Loeber M. Measuring impulsivity and examining its relaiton to delinquency. J Abnorm Psychol 1994; 103: 192-205.

[23] Donnellan MB, Ge X, Wenk E. Personality characteristics of juvenile offenders: Differences in the CPI by age at first arrest and frequency of offending. Pers Individ Dif 2002; 33: 727-40.

[24] Piquero AR, Moffitt TE, Lawton B. Race differences in life-coursepersistent offending. Hawkins D, Kempf-Leonard K, Eds. Our children, their children: Race, development and juvenile justice. Chicago : University of Chicago Press 2005; 202-44.

[25] Paternoster R, Brame R. Missing data problems in criminological research: Two case studies. J Quant Crim 2003; 19: 55-78.

[26] Brame R, Piquero AR. The role of sample attrition in studying the longitudinal relationship between age and crime. J Quant Crim 2003; 19: 107-28.

[27] Nagin DS. Group-based modeling of development over the life course. Cambridge: Harvard University Press 2005.

[28] Piquero AR. Taking stock of developemental trajectories of criminal activity over the life course. Liberman A, Ed. The long view of crime: A synthesis of longitudinal research. New York: Springer 2008; pp. 23-78. 